\title{
Liver Study
}

National Cancer Institute

\section{Source}

National Cancer Institute. Liver Study. NCI Thesaurus. Code C84441.

The examination of the function of the liver using biochemical tests, radiologic procedures, or liver tissue samples. 